\title{
MATa donor preference in yeast mating- type switching: activation of a large chromosomal region for recombination
}

\author{
Xiaohua Wu and James E. Haber ${ }^{1}$ \\ Rosenstiel Basic Medical Sciences Research Center and Department of Biology, Brandeis University, Waltham, \\ Massachusetts 02254-9110 USA
}

\begin{abstract}
During mating-type gene switching in Saccharomyces cerevisiae, DNA at the MAT locus is replaced by sequences copied from one of two unexpressed donor loci, $H M L$ or $H M R$, located near the two ends of the same chromosome and $\geqslant 90 \mathrm{~kb}$ from $M A T$. MATa cells recombine nearly $90 \%$ of the time with $H M L$, whereas MAT $\alpha$ cells select HMR. MATa donor preference was examined by deleting $H M L$ and inserting a donor at other chromosome III locations. MATa activated a large $(\geqslant 40 \mathrm{~kb})$ region near the left end of chromosome III, such that a donor placed at several sites within this domain was strongly preferred over $H M R$. When inserted outside of this domain, the donor was used equally with $H M R$. MATa donor preference for $H M L$ was abolished by the expression of the negative regulator, $M A T \alpha 2$; however, $H M L$ regained its preferred status when the donor was unsilenced. Mating-type-dependent activation of the left end of the chromosome is also observed for other types of recombination that do not involve MAT switching. Spontaneous recombination between two leu2 alleles is 20-30 times higher in MATa than in MATa when one of the leu2 alleles is inserted in place of $H M L$. Transcription in this donor activation region is not affected by mating type. We conclude that $M A T$ a donor preference involves a mating-type-regulated change in the accessibility of a large chromosomal domain for recombination.
\end{abstract}

[Key Words: S. cerevisiae MATa donor preference; mating-type switching; activation; recombination]

Received January 26, 1995; revised version accepted June 26, 1995.

Homothallic switching of the mating-type genes in Saccharomyces cerevisiae occurs by a highly regulated sitespecific recombination event (for review, see Strathern 1989; Haber 1992). The difference between MATa and $M A T \alpha$ cells resides in the $\mathrm{Y}$ region of the mating-type (MAT) locus (Fig. 1). Mating type in heterothallic (ho) strains is stable. Cells carrying the $H O$ allele express the HO endonuclease, which cleaves $M A T$ in the $M A T-Z$ region, near the $M A T-Y / Z$ border, and initiates $M A T$ switching. The double-strand break (DSB) is repaired by gene conversion with one of two unexpressed donor loci, $H M L$ or $H M R$, which are located on opposite arms of the same chromosome, $>90 \mathrm{~kb}$ away from MAT (Fig. 1). The silent $H M$ loci are maintained in a chromatin configuration, different from MAT (Laurenson and Rine 1992), which prevents both transcription and cleavage by the HO endonuclease. However, this altered chromatin structure does not however prevent the ends of the DSB at MAT from invading and copying out new mating-type information to replace the $\mathrm{Y}$ region and adjacent sequences at MAT. The expression of $\mathrm{HO}$ endonuclease is normally confined to the $G_{1}$ phase of the cell cycle but only in mother cells that have previously divided. HO

\footnotetext{
${ }^{1}$ Corresponding author.
}

expression is restricted to haploid MATa or MAT $\alpha$ cells and is turned off in MATa/MAT $\alpha$ diploids or in haploid cells expressing both mating types. However, cells are able to switch $M A T$ at any time in the cell cycle when the $\mathrm{HO}$ gene is expressed from a galactose-inducible promoter (Jensen and Herskowitz 1984; Connolly et al. 1988).

One of the least understood aspects of MAT switching is the phenomenon of donor preference (Klar et al. 1982). MATa cells recombine preferentially $(80 \%-90 \%$ of the time) with $H M L \alpha$, whereas $M A T \alpha$ cells selectively recombine with HMRa (Strathern and Herskowitz 1979). Donor selection is not dictated by the Ya or $\mathrm{Y} \alpha$ sequences, either in the donors or at $M A T$. For example, a $M A T$ a cell carrying genetically distinguishable $H M L \alpha$ and $H M R \alpha$ alleles still uses $H M L$ (Klar et al. 1982). Moreover, when a recessive mata1 mutant is mated with an HO MAT $\alpha$-inc strain (in which the inc mutant cannot be cleaved by $\mathrm{HO}$, the resulting $\alpha$-mating diploid chooses $H M R$ over $H M L$ to replace the mata1 locus (Haber et al. 1980). Donor preference does not depend on any other sequences that uniquely define $H M L$ or $H M R$, as donor preference is maintained if $H M L$ sequences (including its $\mathrm{E}$ and I sites) are swapped with the $H M R$ region and vice versa (Weiler and Broach 1992). Donor preference ap- 

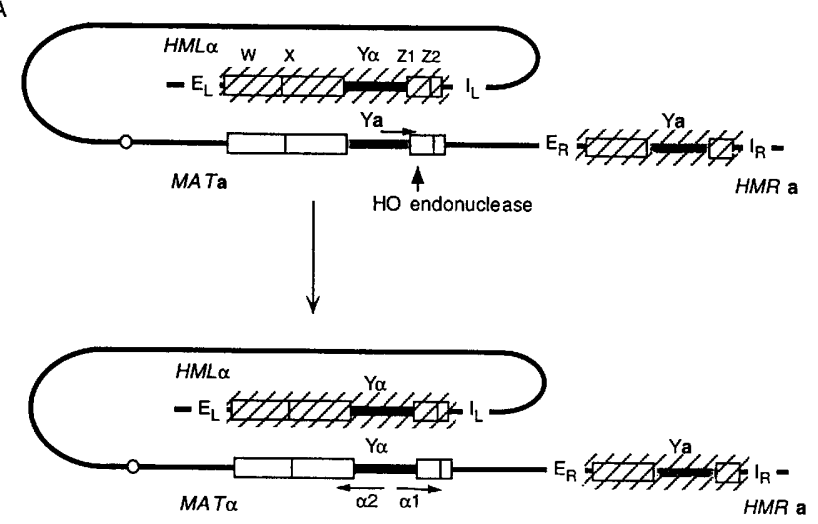

B

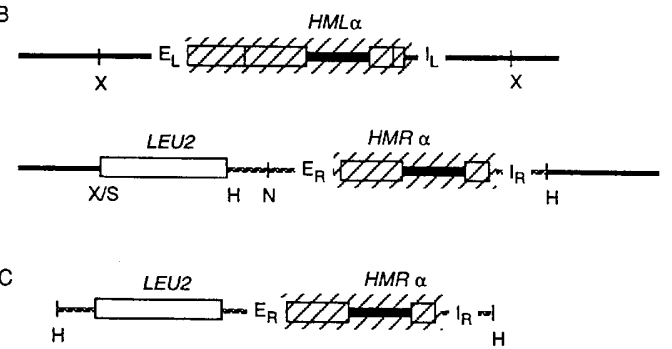

Figure 1. (A) MAT switching in $S$. cerevisiae. HO endonuclease cleaves the MATa locus near the $\mathrm{Y} / \mathrm{Z}$ border and initiates the replacement of Ya sequences with $Y \alpha$ DNA copied from the silent donor $H M L \alpha . M A T \alpha$ encodes two genes, MAT $\alpha 1$ and $M A T \alpha 2$, as shown. MATa encodes a single functional gene, $M A T$ 1. Other shared regions of homology are indicated. The silent donors $H M L$ and $H M R$ are neither transcribed nor cleaved by the $\mathrm{HO}$ endonuclease. Silencing depends on the flanking $\mathrm{E}$ and I sites. $H M L \alpha$ is preferred over $H M R$, even when $H M R$ also carries $\mathrm{Y} \alpha .(B)$ Replacement of a 5.4-kb XhoI (X) fragment containing $H M L$ with a cassette including the $H$ indIII $(\mathrm{H})$ fragment of $H M R \alpha$ adjacent to the $2.2-\mathrm{kb}$ XhoI-Sall (S) LEU2 gene segment. This construction is carried in plasmid pXW135. (C) A similar cassette in plasmid pXW145 containing the LEU2 gene inserted at the NruI site (N) of the HindIII $H M R \alpha$ fragment was inserted at several other chromosomal locations. pears to be an active competition between two competent donors, because when $H M L$ is deleted, a MATa strain switches efficiently using the normally wrong donor, HMR (Klar et al. 1982).

We have discovered that MATa cells activate a large $(\sim 40 \mathrm{~kb})$ region of the left arm of chromosome III, making this region more available for recombination in $M A T$ a cells than in MAT $\alpha$. This activation is not specific for HO-induced mating-type switching but is seen also for general homologous recombination. We show that this activation is under the negative control of the $M A T \alpha 2$ locus and examine the cis-acting sites responsible for this change in accessibility.

\section{Results}

To determine the basic rules for MATa donor preference, we have analyzed the competition between two donors, $H M L \alpha$ and $H M R \alpha-\mathrm{B}$, containing a single-base-pair substitution in $\mathrm{Y} \alpha$ that creates a BamHI site without altering the coded amino acid sequence (see Materials and methods). Thus, a MATa cell can switch to MAT $\alpha$ (from $H M L \alpha$ ) or to $M A T \alpha-\mathrm{B}$ (from $H M R \alpha-\mathrm{B}$ ). In some experiments (Table 1), switching was induced by dissecting HO/HO MATa/MAT $\alpha$ diploids to obtain HO MATa spores. These spores germinate and usually switch mating type at the four-cell stage producing two nonmating $M A T \mathrm{a} / M A T \alpha$ (or two MATa/MAT $\alpha-\mathrm{B}$ ) diploids that then grow up into a colony. The $H O$ gene is turned off in $M A T a / M A T \alpha$ diploids so that there is usually a single switching event, initiated in the $G_{1}$ phase of the cell cycle, that gives rise to the nonmating colony (Strathern 1989). A Southern blot analysis of BamHI-digested DNA, probed with a $\mathrm{Y} \alpha$-specific DNA, distinguishes MATa/ $M A T \alpha$ from $M A T \mathbf{a} / M A T \alpha-\mathrm{B}$ diploids, and therefore demonstrates which donor was chosen. DNA extracted from eight such nonmating colonies was pooled and analyzed together. Four examples of this type of analysis are presented in Figure 2, lanes $1-4$, showing that $H M L$ is preferred $>90 \%$ of the time over $H M R$.

Table 1. Competition between a donor on the left arm of chromosome III vs. HMR $\alpha-B$ in colonies derived from HO MATa spores

\begin{tabular}{llccc}
\hline Strain & $\begin{array}{l}\text { Location of donor } \\
\text { on left arm }\end{array}$ & Donor on right arm & $\begin{array}{l}\text { Number of colonies } \\
\text { analyzed }^{\mathrm{a}}\end{array}$ & $\begin{array}{l}\text { Percentage } \\
\text { using /HMR } \alpha-\mathrm{B}\end{array}$ \\
\hline XW221 & $H M L \alpha$ & $H M R \alpha-\mathrm{B}$ & 32 & 7.5 \\
XW246 & $h m 1 \Delta:: H M R \alpha$ & $H M R \alpha-\mathrm{B}$ & 10 & 15.0 \\
$\mathrm{XW263}$ & $H M R \alpha$ at $91 \mathrm{~kb}^{\mathrm{b}}$ & $H M R \alpha-\mathrm{B}$ & 32 & 49.0 \\
$\mathrm{XW} 348$ & $H M R \alpha$ at $67 \mathrm{~kb}^{\mathrm{b}}$ & $H M R \alpha-\mathrm{B}$ & 32 & 49.3 \\
\hline
\end{tabular}

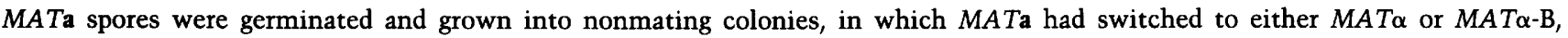
depending on which donor was used. Most homothallic switching occurs at the four-cell stage, in which two cells change to the opposite mating type and then mate with the two cells of the original genotype to produe nonmating $M A T \mathrm{a} / M A T a$ diploids, in which there is no more switching.

${ }^{a}$ Ratio of donor usage determined by densitometry of Southern blots of BamHI-digested DNA that distinguish between MAT $\alpha$ and $M A T \alpha-B$ (see Fig. 2). Except for XW246, 32 or more nonmating colonies were analyzed in mixtures of DNA from eight colonies; and the results averaged. For XW246, 10 colonies were scored in a single mixture, confirming previously published results (Weiler and Broach 1992).

${ }^{\mathrm{b}} \mathrm{A}$ 5.4-kb region containing $H M L$ was deleted by and replaced by the $A D E 1$ gene. 


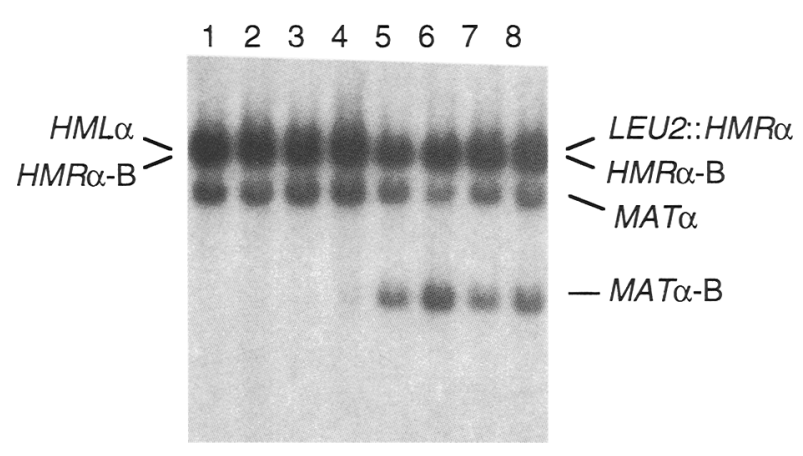

Figure 2. Competition between mating-type donors in MATa homothallic switching. HO MATa spores carrying $H M R \alpha-\mathrm{B}$ and another donor located on the left arm of chromosome III were germinated and grown into nonmating colonies. Each colony results from one, or occasionally more than one, switching event to yield either MATa/MAT $\alpha$ or MATa/MAT $\alpha-\mathrm{B}$ cells. DNA was pooled from eight such nonmating colonies, cut with BamHI and HindIII and separated by gel electrophoresis. The Southern blot was probed with a Y $\alpha$-specific probe. (Lanes 1-4) Four sets of eight pooled colonies of strain XW221 showing a strong preference of $H M L \alpha$ over $H M R \alpha-\mathrm{B}$ (Table 1). (Lanes 5-8) Sets of eight pooled colonies of strain XW263 exhibiting nearly equal usage of $H M R \alpha-\mathrm{B}$ and $L E U 2:: H M R \alpha$, inserted $91 \mathrm{~kb}$ from the left end of chromosome III. The Y $\alpha$ probe hybridizes to the 4.4-kb MAT $\alpha$ or 3.1-kb MAT $\alpha-\mathrm{B}$ BamHI fragments that are produced by switching MATa (which does not hybridize). The probe also hybridizes with the donor sequences, which are all approximately the same size $(H M L \alpha=5.17 \mathrm{~kb}, H M R \alpha-\mathrm{B}=4.98$ $\mathrm{kb}$, and $L E U 2:: H M R \alpha=5.08 \mathrm{~kb}$ ). When the left arm donor is far from $H M L$, it is used about as often as $H M R \alpha-\mathrm{B}$, whereas the $H M L \alpha$ donor itself is used nearly all the time.

In many other experiments reported here, ho MATa cells in liquid culture were induced to switch mating type after a brief galactose induction of a plasmid-borne $G A L:: H O$ gene (Jensen and Herskowitz 1984; White and Haber 1990). Cells are induced to switch at different points of the cell cycle, as opposed to normal HO expression, which is confined to the $G_{1}$ phase of the cell cycle (Jensen and Herskowitz 1984; Connolly et al. 1988). About $60 \%-80 \%$ of ho MATa $H M L \alpha H M R \alpha-\mathrm{B}$ cells changed mating type after a 1.5 -hr induction (White and Haber 1990). BamHI-digested DNAs from individual $\alpha$-mating colonies were analyzed by Southern blots or by PCR amplification (see Materials and methods). Most cells gave rise to either MAT $\alpha$ or MAT $\alpha-\mathrm{B}$, but $\sim 5 \%$ $10 \%$ of the colonies were mixed, presumably because switching was initiated in cells that had already replicated their chromosomes and each chromosome acted independently (Connolly et al. 1988). The results obtained by galactose induction of $H O$ were the same as those obtained with the normal HO gene: In both strains XW221 and XW431, MATa switched $>90 \%$ of time us-

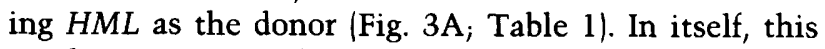
result is important because it shows that donor preference is the same when the normal $\mathrm{HO}$ gene is expressed in the $G_{1}$ phase of the cell cycle or when the galactoseinducible $H O$ gene is expressed throughout the cell cy- cle. These two different methods of $H O$ induction also give similar results in cases where normal donor preference was altered (see below).

\section{Competition between donors defines a large MATa- activated region at the left end of chromosome III}

To understand which DNA sequences around $H M L$ or $H M R$ are important to establish donor preference, we created a large set of strains in which the $5.4-\mathrm{kb}$ region, including the $H M L$ locus and all of the surrounding silencer sequences, were deleted and $H M R \alpha$ and its adjacent silencers were inserted at different locations (Fig. 3). In agreement with Weiler and Broach (1992), we found that inserting $H M R \alpha$ directly in place of $H M L \alpha$ (Fig. 1B) gave the same donor preference as $H M L \alpha$ (Table 1, cf. strains XW221 and XW246). We then created strains in which $H M L$ was deleted and $H M R \alpha$ was inserted at four different locations on the left arm of chromosome III. When HMR was inserted near HIS4 or LEU2 167 or $91 \mathrm{~kb}$ from the left end), there was no preference in the use of the donor on the left chromosome arm over $H M R \alpha$-B (Fig. 3E,F). In these situations, the two donors, located approximately equidistant from MAT on two different chromosome arms, are used equally (Fig. 3; Table 1). One example, for the competition between $L E U 2:: H M R \alpha$ and $H M R \alpha-\mathrm{B}$, is shown by the Southern blot in Figure 2, lanes 5-8. The results were the same whether $H O$ was induced by galactose (Fig. 3, XW453, XW452) or by its natural expression (Table 1, XW348, XW263). These results rule out models in which all donor sites to the left of the centromere or to the left of MATa would be preferred over $H M R$. Also excluded are mechanisms in which $H M R$ is specifically sequestered or inactivated so that it cannot act efficiently in competition with another donor.

However, the region immediately around $H M L$ is not the only preferred domain. When $H M L$ was deleted and the donor on the left arm was placed at locations 22 or 41 $\mathrm{kb}$ from the left end of chromosome III (strains XW426 and XW427), the donor on the left arm was clearly preferred, just as at $H M L$ itself (Fig. 3C,D). This suggests that MATa cells activate not simply the region around $H M L$ but a large $(\geqslant 40 \mathrm{~kb})$ chromosomal region to be especially recombinogenic during MATa switching.

Donor preference was also seen when the normal $H M R$ locus was deleted and the strain carried two donors on the left arm, one at $H M L$ and a second at HIS4 $(67 \mathrm{~kb})$. In this strain (XW486) (Fig. 3)), the donor at HIS4 was $H M L \alpha-\mathrm{H}$, carrying a HindIII site in Y $\alpha$. Among the MATa cells that switched, $75 \%$ used the $H M L \alpha$ locus and $25 \%$ used the donor at HIS4. This confirms that the donor preference mechanism can discriminate between two locations on the left arm of chromosome III.

Finally, to assess whether the proximity of either $H M L$ or $H M R$ to a telomere plays an important part in the regulation of donor preference, we constructed a MATa strain in a circular chromosomal derivative of chromosome III that contains a single, recombined $H M R / H M L \alpha$ locus and lacks all sequences distal to both donors 

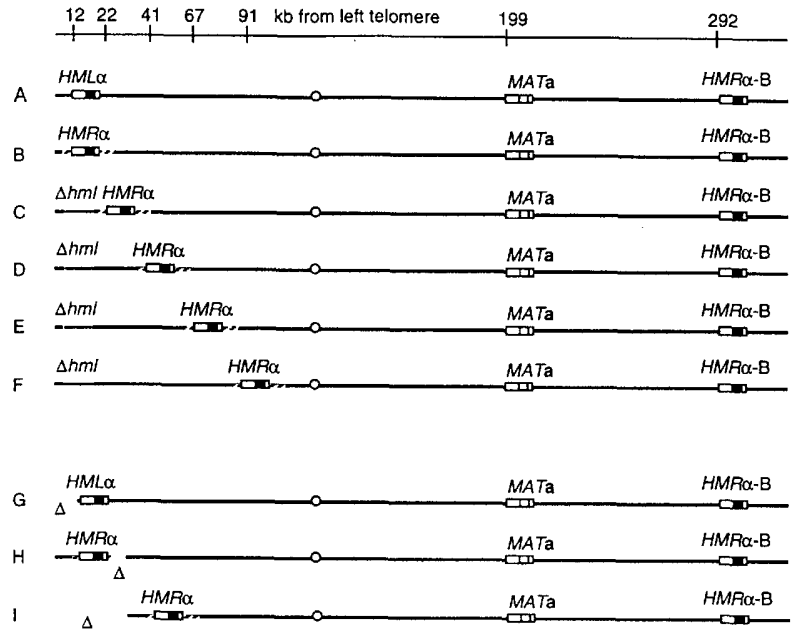

$\mathrm{J}$

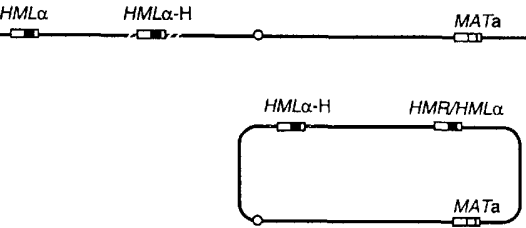

Proportion of switches using $H M R \alpha-B$ as donor

$10 \%$

$15 \%$

$24 \%$

$12 \%$

$56 \%$

$50 \%$

$19 \%$

$12 \%$

$28 \%$

Proportion of switches using $H M L \alpha-H$ as donor

$25 \%$

$15 \%$

Figure 3. Effect of position of a donor located to the left of MATa on donor preference. Normal switching involves a competition between $H M L \alpha$ and $H M R \alpha-\mathrm{B}$, carrying a $B a m H I$ site that permits the two sequences to be distinguished $(A)$. Except for XW246, all strains were analyzed with a minimum of 26 independent $\alpha$-mating colonies (up to a maximum of 72 colonies) produced after induction of MATa switching using the $G A L:: H O$ gene. A small minority of colonies gave evidence of mixed events, in which both MAT $\alpha$ and MAT $\alpha$-B cells were present. These presumably arose when $\mathrm{HO}$ was induced in a cell that had completed DNA replication and thus could give rise to two independent switching events (Connolly et al. 1988). The proportion of cells using $H M R \alpha-\mathrm{B}$ as the donor was then determined by counting these events as two independent events and adding half their number to the totals for both MATa and MAT $\alpha-\mathrm{B}$. Results for strain XW246 are based on the experiment described in Table 1 . When $H M L$ and its surrounding sequences are deleted and reXW526 placed by $H M R \alpha$, donor preference still favors the donor on the left chromosome arm $(B)$. A series of strains were constructed in which $H M L$ was deleted and the $H M R \alpha$ locus and an adjacent $L E U 2$ gene were inserted at several other chromosomal locations: $(C) 22 \mathrm{~kb}$ from the left chromosome end; $(D) 41 \mathrm{~kb} ;(E) 67 \mathrm{~kb}$; and $(F) 91 \mathrm{~kb}$. Terminal deletions of chromosome III were constructed by the gene targeting Tetrahymena telomere sequences to create a new telomeric end. A deletion of the terminal $12 \mathrm{~kb}$ $(G)$ and $22 \mathrm{~kb}(I)$ were constructed. An internal deletion of sequences to the right of $H M L(H)$ was constructed by homologous recombination/replacement of the region from the left of $H M L$ (nucleotide 11,294) to nucleotide 21,974 with an insert containing LEU2 and HMR $\alpha$ (see Fig. 1), thus effectively removing the $8 \mathrm{~kb}$ that normally lies to the right of $H M L$. Strain XW486 (J) is deleted for $H M R$ and carries $H M L \alpha$ at its normal location and the 6.6-kb BamHI fragment of $H M L \alpha-H$ inserted at HIS4 (67 kb). Strain XW526 carries a circular chromosome $(K)$ containing a fusion of $H M R$ and $H M L$ (Haber et al. 1984) and also the insertion of $H M L \alpha-H$ at $H I S 4$ $(67 \mathrm{~kb})$.

(Haber et al. 1984). A second donor, $H M L \alpha-\mathrm{H}$, was then inserted at the HIS4 locus, outside of the region of preferential donor activation (Fig. 3K). After GAL::HO induction, $>80 \%$ of the switches of this strain (XW526) came from $H M R / H M L \alpha$, suggesting that donor preference does not involve a telomere-dependent activation of $H M L$ in MATa cells. These results are essentially the same as those for the linear chromosome version of this experiment (Fig. 3J, strain XW486) described above. They also suggest that sequences needed to activate $H M L$ are proximal to $H M L$ las all $H M L$-distal sequences are missing); moreover, there are no sites proximal to $H M R$ that prevent the use of an adjacent donor in MATa cells.

\section{Cis-acting regions responsible for MATa donor preference lie $\geqslant 10 \mathrm{k} b$ from $\mathrm{HML}$}

The activation of $H M L$ and the rest of a large chromosomal domain in MATa cells must involve cis-acting sites on the left arm of chromosome III. We have constructed a number of deletions to identify those sites. We created deletions of $12 \mathrm{~kb}$ to the left of $H M L$ (Fig. 3G) or $8 \mathrm{~kb}$ to the right of $H M L$ (Fig. $3 \mathrm{H}$ ), neither of which had any significant effect on $M A T$ a donor preference. To construct a larger deletion we began with the strain illustrated in Figure 3D, where the donor is located $41 \mathrm{~kb}$ from the chromosome end, which is still in the region where the donor is activated in MATa cells. A terminal deletion of $22 \mathrm{~kb}$ was then constructed by the insertion of a new telomere sequence (Fig. 3I). Despite the removal of $\sim 10 \mathrm{~kb}$ of the sequences normally found on either side of $H M L, M A T$ a donor preference remained unchanged. Thus, any cis-acting sequences responsible for establishing MATa donor preference are located far from the location of the normal $H M L$ locus. Larger deletions of this region are haploid-inviable, so that further analysis will require that essential genes in this interval be duplicated elsewhere.

\section{MATa donor preference is regulated by MAT $\alpha 2$}

An early study of MAT switching (Tanaka et al. 1984) suggested that the repressor of a-specific gene expression, $M A T \alpha 2$, might play a decisive role in regulating donor preference. An $H O$ hmla2 mata2 HMRa cell switched only rarely to MATa, suggesting that mata2 
cells were a-like in their donor preference. However, the pedigree studies on which this was based could not rule out the possibility that the mat 22 mutation itself reduced the frequency of $\mathrm{HO}$ cleavage and switching, which would have yielded a similar result. Here we show that $M A T \alpha 2$, expressed in trans, does regulate donor preference. A $G A L:: H O$ strain, XW431, of genotype $M A T$ a $H M L \alpha H M R \alpha$-B was transformed with either the $M A T \alpha 1$ gene or the MAT $\alpha 2$ gene inserted at $U R A 3$ on chromosome $\mathrm{V}$ (Fig. 4A,B). The MATa1 gene carries an inc mutation so that it is not cut by HO. The ectopic expression of either MATa1 or MATa2 causes a MATa cell to become nonmating, but for different reasons. In the case of MAT 1 , both a-specific and $\alpha$-specific genes are expressed simultaneously, whereas in the case of $M A T \alpha 2$, both a-specific and $\alpha$-specific genes are turned off. We induced the $H O$ gene and recovered $\alpha$-mating switched cells that were either MAT (from $H M L$ ) or

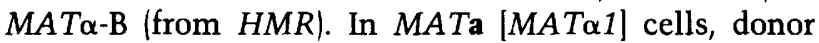
preference remained in favor of $H M L$, but in MATa [MAT $\alpha 2]$ cells donor preference shifted to that expected

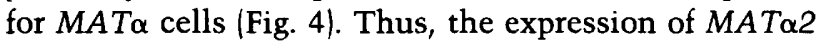
prevents the activation of $H M L$. Whether MAT 2 also increases the accessibility of $H M R$ is not established by this experiment.

\section{Role of silencing in regulating HML donor accessibility}

One of the most interesting aspects of the mating-type system in yeast is that the chromatin structure of the donors make them inaccessible to cleavage by $\mathrm{HO}$ endonuclease, yet the HO-cleaved ends of MAT are able to invade the same site in the donor and begin to copy the donor DNA. Thus, one simple way to control donor preference would be to regulate a donor's degree of accessibility to strand invasion by MAT DNA. For example, the wrong donor could be hypersilenced, so that MAT DNA would be less able to invade it. Alternatively, the struc- ture of the preferred donor could be somewhat relaxed to be more available (though not to the extent that the silent donor would be cut by HO or be transcribed). We have tested an extreme version of this idea by asking if an unsilenced donor would be used preferentially even when normal MATa preference is abolished. As noted above, in strain XW425, a MATa cell that also expresses $M A T \alpha 2$ shifts its donor preference to $H M R$. We constructed a related strain, XW490, in which the $5.4-\mathrm{kb}$ region, including $H M L \alpha$ and its adjacent silencer sequences, was replaced with a $6.4-\mathrm{kb} E c o \mathrm{RI}$ fragment of $M A T \alpha$-inc, which lacks the adjacent $\mathrm{E}$ and I silencer sites (Fig. 4C). This $\left(\mathrm{E}^{-} \mathrm{I}^{-}\right)$hml $1:: M A T \alpha$-inc MATa $H M R \alpha-\mathrm{B}$ strain is nonmating because both MATa and MATa2 (from $h m l \Delta:: M A T \alpha$-inc) are expressed. MAT 1 is not expressed in diploids expressing both MATa and MAT 2 (Herskowitz 1989); thus, this cell is phenotypically equivalent to XW425. Only MATa can be cleaved by HO, and thus the cell can either use the expressed $h m l \Delta:: M A T \alpha$-inc or the silent $H M R \alpha-\mathrm{B}$ as a donor. Unlike strain XW425, where donor preference shifted to $H M R \alpha-\mathrm{B}$, this nonmating strain continues to prefer the donor located at $H M L$. We conclude that donor preference can be significantly altered by "opening up" a silent donor.

\section{$A$ LEU2 gene in place of HML recombines more frequently in MATa than in MAT $\alpha$}

The activation of $H M L$ in MATa cells is not restricted to mating-type sequences or to recombination initiated by the HO endonuclease. We show below that spontaneous recombination between leu2 heteroalleles to yield Leu ${ }^{+}$ recombinants is also increased in MATa cells when one of the two alleles is inserted in place of $H M L$. A $5.4-\mathrm{kb}$ $X$ hol segment including $H M L$ and its surrounding $\mathrm{E}$ and I silencer sites was replaced with the 2.2 -kb fragment containing the mutant allele of the $L E U 2$ gene, leu2-R. A
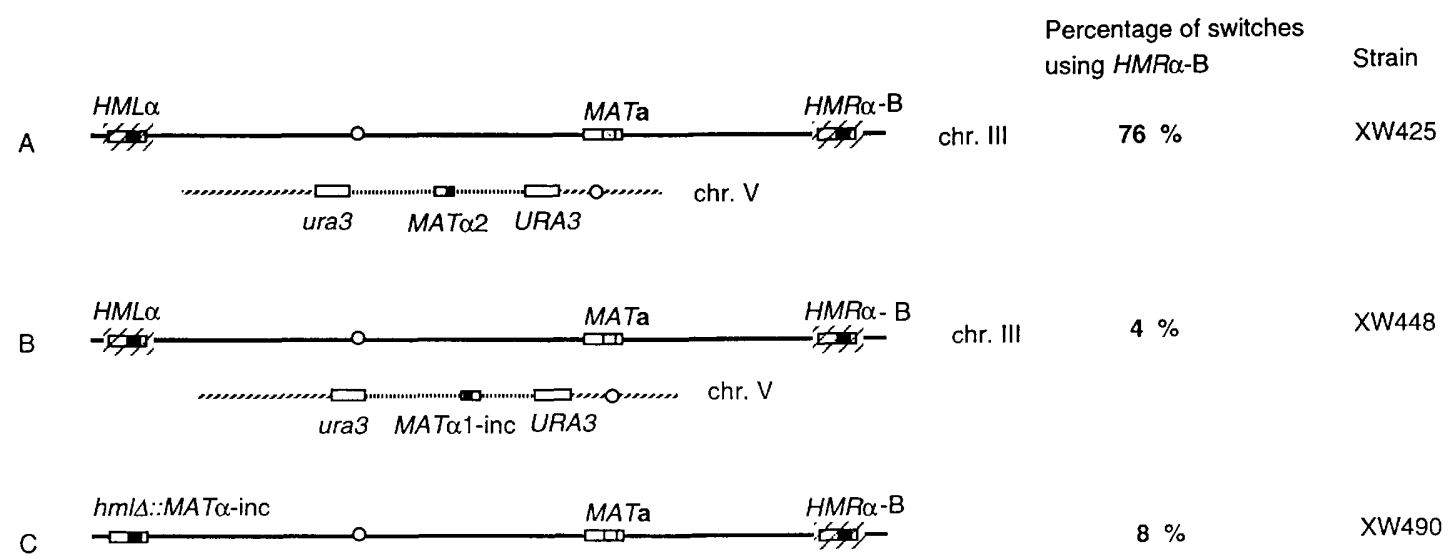

Figure 4. Ectopic expression of the MAT 1 or MAT $\alpha 2$ genes in MATa strains. A URA3-marked plasmid carrying either the MAT 2 gene $(A)$ or the $M A T \alpha 1(B)$ gene was inserted by homologous integration at the ura3-52 locus on chromosome V. The MATa1 gene was PCR amplified from a $M A T \alpha$-inc strain and thus contains a single base-pair mutation that prevents HO cutting (Weiffenbach et al. 1983). The MAT $\alpha 2$ gene is expressed along with MATa in strain XW490, in which $M A T \alpha$-inc is inserted in place of $H M L(C)$; thus, this strain has the same effective genotype as strain XW425 $(A)$. 
different allele, leu2- $K$, was inserted between two tandem repeats of either MATa or MAT $\alpha$ (Fig. 5B). The rate of spontaneous recombination to $\mathrm{Leu}^{+}$prototrophy was 30 times higher in MATa than in MATa cells (Table 2). Thus, a spontaneous recombination event that does not involve mating-type sequences exhibits the same sort of mating-type-controlled preference as $M A T$ switching itself. This difference is easily visualized when a $[M A T \mathbf{a}-$

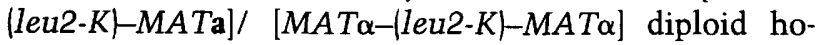
mozygous for $h m l \Delta::(l e u 2-R)$ was sporulated and dissected (Fig. 6). In every tetrad there were two segregants (both MATa) that had a much higher level of $\mathrm{Leu}^{+}$papillae when the colonies were replica-plated to leucine dropout medium.

The increased recombination of $h m l \Delta::(l e u 2-R)$ in $M A T$ a cells could either be because there is a more efficient donor or a more avid recipient. We could determine which allele was converted in strains XW499 and XW500 by "popping out" the MAT-URA3-LEU2-MAT duplication, selecting for $\mathrm{Ura}^{-}$colonies on 5 -fluoro-orotic acid (5-FOA) medium (Boeke et al. 1987). If the duplication carried the converted $\mathrm{Leu}^{+}$locus, then the Ura ${ }^{-}$derivatives would become also $\mathrm{Leu}^{-}$. If $h m l \Delta::(1 e u 2-R)$ had been converted, the strain would remain $\mathrm{Leu}^{+}$. In the $M A T \alpha$ strain, 50/55 $(91 \%)$ became Leu ${ }^{-}$, indicating that the leu2-K allele adjacent to MAT had been converted. In the MATa strain, this proportion did not change: $50 / 54$ $(93 \%)$ converted the leu2- $K$ allele. In previous experiments we have found that leu2- $K$ is converted more frequently to wild type than is leu2- $R$ when they are at the same chromosomal location; however, when the two alleles are in different locations, the proportion of leu2- $R$ alleles that is converted to wild type can be increased if it is situated in the site that is most often the recipient in the recombination event (Lichten et al. 1987; Lichten and Haber 1989). In the present case, it appears that the mating-type-dependent activation of $h m l \Delta::(l e u 2-R)$ oc- curs without making it the recipient. Instead, $h m l \Delta:(1 e u 2-R)$ locus is activated to be a more efficient donor during these spontaneous recombination events, as it is in MAT switching.

The high level of $\mathrm{Leu}^{+}$recombination in MATa cells does not require pairing sites that might be postulated to align $H M L$ and $M A T$, because similar results were obtained when $h m l \Delta:: l e u 2-R$ recombined with a leu2- $K$ allele situated at its normal location, $\sim 100 \mathrm{~kb}$ from $M A T$ (Fig. $5 \mathrm{C}$ ). $\mathrm{Leu}^{+}$recombinants arose 20 times more frequently in MATa cells than in MATa (Table 2). Recombination between $h m l \Delta::(l e u 2-R)$ on chromosome III and leu2-K integrated near URA3 on chromosome $\mathrm{V}$ was again much higher in MATa (Fig. 5D; Table 2). We also note that there is an intrinsically higher rate of intraversus interchromosomal recombination, as expected from previous studies of recombination between these same two alleles (Lichten and Haber 1989).

In general, MATa cells do not have higher levels of leu2 recombination than $M A T \alpha$. Strains with leu2-K at its normal location and leu2-R at MAT displayed no mating-type effect on the rate of $\mathrm{Leu}^{+}$recombination (Fig.

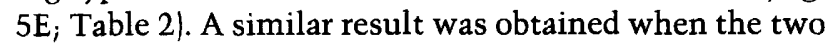
leu2 alleles were inserted at two other chromosome III locations, 162 and $233 \mathrm{~kb}$ from the left end of the chromosome, respectively (Fig. 5F; Table 1 ).

\section{Elevated recombination of $\mathrm{hml} \Delta:: \mathrm{leu} 2$ is repressed in MATa cells expressing MAT $\alpha 2$}

To determine whether $M A T \alpha 2$ also regulates the activation of $h m l \Delta::(l e u 2-R)$ recombination, as it does MATa donor preference, we constructed the nonmating strain XW498 of genotype MATa-URA3-(leu2-K)-MAT $\alpha$, which could be compared with those carrying two tandem copies of MATa (XW499) or MATa (XW500). A similar set of strains (XW529, XW530, and XW531) were

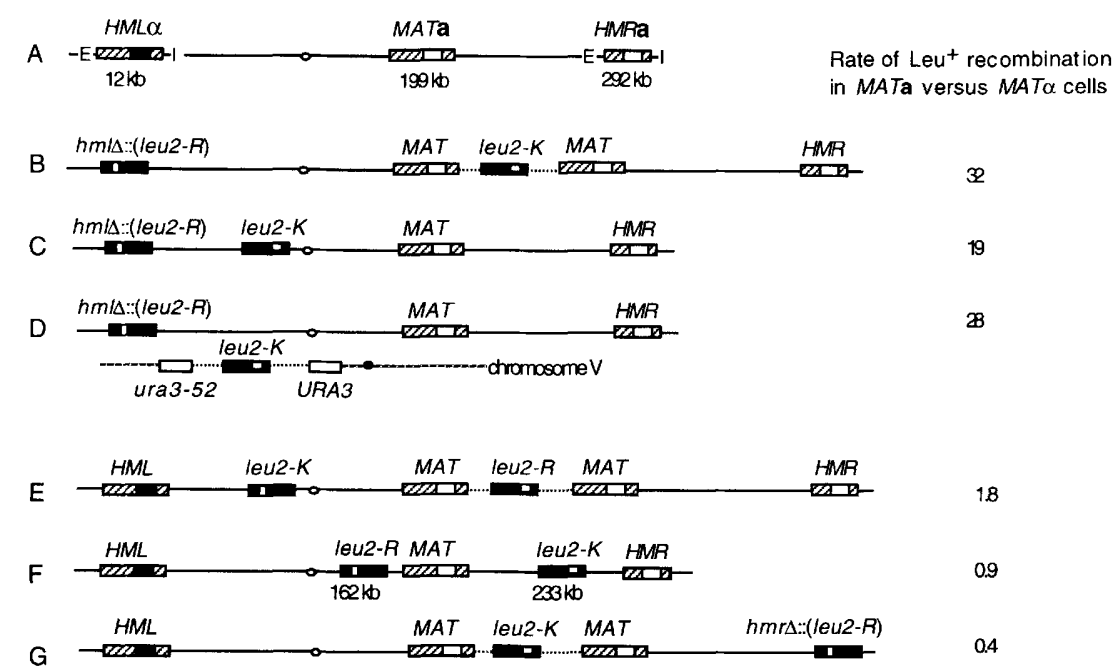
mating-type effect, in favor of $M A T \alpha$, when it recombines with a leu2- $K$ allele adjacent to $M A T$. The ratio of the rates of recombination in MATa vs. MATa cells is presented. nation of leu2 heteroalleles. An XhoI fragment containing $H M L$ and its adjacent silencer $E$ and $I$ regions was deleted and replaced with a 2.2 -kb fragment containing the leu2- $R$ allele. This allele can recombine with a leu2- $K$ that was inserted at other chromosomal locations on chromosome III $(B, C)$ or chromosome $\mathrm{V}(D)$. Except when the normal leu2 locus itself was tested for recombination, it was deleted. The strong mating-type effect on the rate of $\mathrm{Leu}^{+}$recombination is not seen when leu2- $K$ is inserted at its normal location and leu2-R is adjacent to $M A T(E)$. No matingtype effect is seen when the two leu2 alleles are placed at two other chromosome III locations $(F)$. A similar replacement by leu2- $R$ of the NruI-XhoI fragment of $H M R$, including sequences 250 bp proximal and 300 bp distal, was constructed $(G)$. This shows only a small

Figure 5. Mating-type-dependent recombi- 
Table 2. Effect of mating type on the rate of LEU2 prototroph formation between leu2 alleles in different chromosomal locations

\begin{tabular}{|c|c|c|c|c|c|c|}
\hline \multirow[b]{2}{*}{ Strain } & \multirow{2}{*}{$\begin{array}{l}\text { Mating } \\
\text { type }^{\mathbf{a}}\end{array}$} & \multicolumn{2}{|c|}{ Location of } & \multirow{2}{*}{$\begin{array}{l}\text { Rate of } \\
\mathrm{Leu}^{+}\end{array}$} & \multicolumn{2}{|c|}{ Ratio } \\
\hline & & leu2-R & leu2-K & & $\mathbf{a} / \alpha$ & $\mathrm{nm} / \alpha^{\mathrm{a}}$ \\
\hline XW499 & $\mathbf{a}$ & $H M L$ & $M A T$ & $6.72 \times 10^{-6}$ & 32 & \\
\hline XW500 & $\alpha$ & $H M L$ & $M A T$ & $2.13 \times 10^{-7}$ & & \\
\hline XW498 & $\mathrm{nm}$ & $H M L$ & $M A T$ & $1.34 \times 10^{-6}$ & & 6.3 \\
\hline XW440 & $\mathbf{a}$ & $H M L$ & LEU2 & $5.82 \times 10^{-6}$ & 19 & \\
\hline XW421 & $\alpha$ & $H M L$ & LEU2 & $3.01 \times 10^{-7}$ & & \\
\hline XW485 & $\mathbf{a}$ & $H M L$ & URA3 & $3.06 \times 10^{-7}$ & 28 & \\
\hline XW456 & $\alpha$ & $H M L$ & URA3 & $1.10 \times 10^{-8}$ & & \\
\hline XW529 & $\mathbf{a}$ & $M A T$ & LEU2 & $2.15 \times 10^{-7}$ & 2.3 & \\
\hline XW530 & $\alpha$ & $M A T$ & LEU2 & $9.20 \times 10^{-8}$ & & \\
\hline XW531 & $\mathrm{nm}$ & $M A T$ & LEU2 & $3.38 \times 10^{-7}$ & & 3.7 \\
\hline H334 & $\mathbf{a}$ & $M A T$ & LEU2 & $2.37 \times 10^{-7}$ & 1.8 & \\
\hline H333 & $\alpha$ & $M A T$ & LEU2 & $1.31 \times 10^{-7}$ & & \\
\hline XW412a & $\mathbf{a}$ & $162 \mathrm{~kb}^{*}$ & $233 \mathrm{~kb}^{*}$ & $6.12 \times 10^{-7}$ & 0.88 & \\
\hline XW412 & $\alpha$ & $162 \mathrm{~kb}^{*}$ & $233 \mathrm{~kb}^{*}$ & $6.93 \times 10^{-7}$ & & \\
\hline XW508 & $\mathbf{a}$ & $H M R$ & $M A T$ & $6.79 \times 10^{-7}$ & 0.42 & \\
\hline XW506 & $\alpha$ & $H M R$ & $M A T$ & $1.62 \times 10^{-6}$ & & \\
\hline
\end{tabular}

The leu2- $K$ and leu2- $R$ alleles (Lichten et al. 1987) were inserted into different chromosomal locations on chromosome III. (162 kb* and $233 \mathrm{~kb}^{\star}$ ) Locations from the left end of chromosome III as determined by Oliver et al. (1992) (see Materials and methods). Except when the normal $L E U 2$ locus was specifically involved in recombination, the locus was deleted by the removal of the XhoI-EcoRV segment including both the leu2-K and leu2-R sites (E.J. Louis and J.E. Haber, unpubl.). The rates of LEU2 prototroph formation was determined by a fluctuation test (Lea and Coulson 1949) based on a minimum of five independent cultures of each strain, initiated from 20 to 80 cells and grown to saturation. The LEU2 genes in these constructions are all oriented with the $5^{\prime} \rightarrow 3^{\prime}$ direction being left to right on the chromosome, as shown in Figure 5, except for the hml $::(l e u 2-R)$ and $249 \mathrm{~kb}:($ leu2-K) insertions on chromosome III. ${ }^{\mathrm{a}}(\mathrm{nm})$ Nonmating.

obtained where the leu2 alleles are at leu2 locus itself and MAT. The results shown in Table 2 show a four- to sixfold increase of recombination in nonmating derivatives over $M A T \alpha$, whether the leu2 sequences are at the

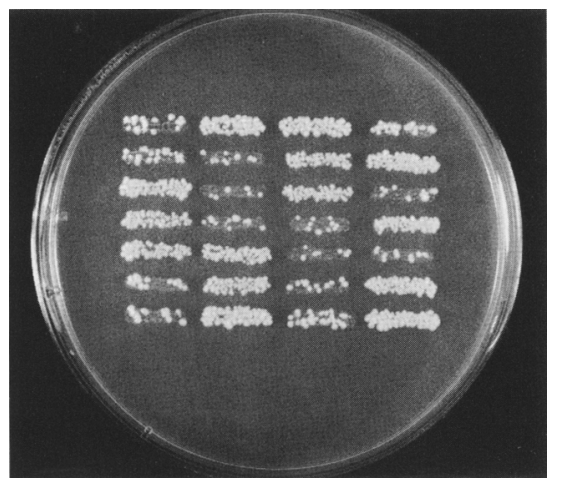

Figure 6. Mating-type dependence on the formation of $\mathrm{Leu}^{+}$ recombinants. A diploid of genotype [MATa-(leu2-K)-MATa/ $M A T \alpha-(l e u 2-K \mid-M A T \alpha]$ and carrying $h m l \Delta:: l e u-R$ was constructed (see Fig. 5B). The diploid was sporulated, and the four spores of each tetrad were dissected. Each row represents the two MATa and two MAT $\alpha$ colonies derived from one tetrad, which were replica-plated from rich medium to synthetic medium lacking leucine. The frequency of $\mathrm{Leu}^{+}$prototrophs is much higher in two of the four segregants, both of which are $M A T a$. In the first row, e.g., the first and fourth segregants are $M A T \alpha$ and the middle two are MATa. In the second row, the two patches on the left are from MAT $\alpha$ and the two on the right are from $M A T \mathbf{a}$.
$H M L$ site or not. This is expected in view of other studies showing that nonmating (MATa/MAT $\alpha$ ) diploids exhibit higher levels of spontaneous recombination in general over strains homozygous for one mating type (Friis and Roman 1968; Durand et al. 1993). Thus, nonmating cells have an elevated level of recombination relative to $M A T \alpha$ cells, but there is no longer any positional effect as observed in MATa cells. We conclude that expression of $M A T \alpha 2$ represses the $M A T \mathrm{a}$-dependent high level of leu2 heteroallelic recombination for $h \mathrm{ml} \Delta:($ leu2-R) in the same way that donor preference in mating-type switching is repressed.

\section{A LEU2 gene in place of HMR does not show strong mating-type preference}

A similar experiment was carried out to determine whether MAT $\alpha$ cells would preferentially activate recombination of a leu2-R allele inserted in place of $H M R$ (Fig. 5G). Here, we found a 2.5-fold preference for $M A T \alpha$ over MATa (Table 2), which is a much more modest effect, though statistically significant.

Activation of the region around HML for recombination is not accompanied by a change in the level of transcription

One general type of model to explain the mating-typedependent activation of the region including $H M L$ for 
recombination is that there is also a general increase in transcription, as it has been shown previously that recombination is increased when a gene is transcribed than when it is not (Thomas and Rothstein 1989). This does not seem to be the case here. We used Northern blots to examine the level of LEU2 mRNA in MATa and MAT $\alpha$ isogenic strains carrying $h m l \Delta:: L E U 2$ and deleted for the normal LEU2 locus [these strains were the precursors of strains XW499 and XW500 that showed MATa-dependent elevation of leu2 recombination (Table 2)]. There was no significant difference in the abundance of LEU2 mRNA (data not shown).

\section{Discussion}

When MATa is cut by HO endonuclease, the DSB must be repaired by recombination. There is a competition between alternative donors located on the same chromosome (Klar et al. 1982). The preferential use of $H M L$ over $H M R$ does not result from inactivating or sequestering $H M R$, as $H M R$ is used equivalently to donors located elsewhere on the chromosome, but outside of the donor activation region (DAR) that includes $H M L$. The observations that we have presented suggest that MATa donor preference results from the activation of $H M L$ to be more available for recombination than $H M R$ or than donors located in many other positions. However, the region immediately around $H M L$ is not unique in being activated. MATa cells activate donors at (at least) two other positions in a large region $\geqslant 40 \mathrm{~kb}$ at the left arm of chromosome III so that they also recombine more efficiently with MAT than do donors at other chromosomal locations. The activation of this region does not depend specifically on sequences surrounding $H M L$, as $H M R$ will work just as efficiently in place of $H M L$ (Weiler and Broach 1992) or at other sites in this $40-\mathrm{kb}$ region (our data). The activation of this region does not depend on any of the sequences defining mating-type donors, as leu2 sequences situated in the DAR are also activated for recombination in $M A T$ a cells.

Another model that might have explained donor preference would be the existence of pairing sites adjacent to $H M L$ and $M A T$ that permit a prealignment of the donor when an a-specific gene product is expressed. However, the idea of specific pairing sites between $M A T$ and $H M L$ seems less likely given that MATa cells prefer donors located at several positions within a $40-\mathrm{kb}$ region at the left end of chromosome III. Moreover, the leu2 recombination experiments show that a leu2 allele in place of $H M L$ is activated in MATa cells even when the other leu2 is on a different chromosome.

$M A T$ a donor preference is preserved even if the terminal $22 \mathrm{~kb}$ of the left arm of chromosome III is deleted. Thus, there are cis-acting sequences, sufficient to ensure $M A T$ a donor preference, that lie at least $10 \mathrm{~kb}$ proximal to the original $H M L$ site. Further analysis of this region will require complementation of essential genes lying between 22 and $41 \mathrm{~kb}$ (X. Wu, unpubl.).

Another possibility is that the terminal $40 \mathrm{~kb}$ of chromosome III is prevented from interacting with DNA se- quences located elsewhere in the genome but that this constraint is released in MATa cells. For example, the DAR could be anchored to the nuclear envelope, similar to the SIR gene-dependent tethering of telomere regions (Palladino et al. 1993), in MAT $\alpha$ cells but released in $M A T \mathbf{a}$. If there is such a release of this region of the chromosome, it does not apparently involve inactivation of the SIR genes, as $H M L$ remains silent in MATa cells and physical analysis of MATa switching has demonstrated that the $H M L$ locus remains refractory to $\mathrm{HO}$ cleavage (Connolly et al. 1988). Nevertheless, the state of silencing does influence donor preference. As we showed above, the repression of $H M L$ recombination in a $M A T \mathbf{a}$ cell expressing $M A T \alpha 2$ can be overcome by providing an unsilenced $h m l \Delta: M A T \alpha$-inc donor at the position of $H M L$. Thus, there seems to be a hierarchy of structural features that dictate donor preference: Normally, a silenced $H M L$ is efficient in MATa switching, but an unsilenced donor at the same position can overcome the loss of the normal activation mechanism. The identification of a cis-acting sequence responsible for activating the donors in MATa cells should provide some indication of the way in which these sequences may be used.

There are other indications that the left-most $40 \mathrm{~kb}$ of chromosome III is unusual in its structure. For example, Collins and Newlon (1994) have surveyed the activity of 14 DNA sequences found on the left two-thirds of chromosome III, which were shown to act as origins of replication on plasmids [so-called autonomously replicating sequences (ARSs)]. However, only six of these ARS sequences appear to have bona fide origin of replication activity on the chromosome. Most of the inactive origins are in the $40-\mathrm{kb}$ region identified by our study. This may suggest that the region has an unusual chromosome structure where accessibility to replication /and recombination) machinery may be constrained. Whether more of these origins would be active in diploids, where a- and $\alpha$-specific genes are repressed, is not known. The MATadependent activation of DAR reminds us of $\mathrm{X}$ chromosome dosage compensation in Drosophila males (Bone et al. 1994|, where transcription is increased over that in females, presumably because male-specific gene products bind to activation sites on the $\mathrm{X}$ chromosome. In yeast, the activation of DAR apparently requires the action of an a-specific gene product whose expression is turned off by $M A T \alpha 2$. We imagine that this a-specific protein binds to one or more cis-acting sites in DAR. The activation of DAR is sufficient to increase spontaneous leu2 recombination by 20 - to 30 -fold. However, the change in accessibility of the donor must be accomplished without unsilencing the donor. Unlike the Drosophila case, there is no mating-type-dependent change in the level of transcription of a gene that we showed was activated for recombination.

\section{MATa donor preference operates differently from MAT $\alpha$ donor selection}

In this paper we have focused our attention on MATa donor preference. How MAT $\alpha$ cells choose $H M R$ is not 
yet clear, but several lines of evidence argue that $M A T \alpha$ donor preference for $H M R$ is not simply the mirror image of how DAR is activated in MATa. For example, we have observed that HO MAT $\alpha$ cells deleted for HMR are not efficient in using $H M L \alpha$ as a "backup" donor, whereas $H O M A T$ a cells switch efficiently using HMRa when $H M L$ is deleted. About one half of MATa cells die when they are provided only with the "wrong donor" because they fail to repair the DSB (X. Wu, J.K. Moore and J.E. Haber, unpubl.). Furthermore, MATa cells do not show a significant activation of leu2 heteroallelic recombination when one of the alleles is situated in place of $H M R$. Finally, we have shown recently that, whereas $H M L \alpha$ on chromosome III can act efficiently to switch MATa inserted on chromosome $\mathrm{V}, H M R$ a fails to repair a DSB at MAT $\alpha$ on chromosome V $>95 \%$ of the time (C. Wu, X. $\mathrm{Wu}, \mathrm{N}$. Rudin, and J.E. Haber, unpubl.). Further experiments are under way to analyze MAT $\alpha$ donor preference.

\section{Relation of S. cerevisiae donor preference to programmed chromosomal rearrangements in other organisms}

Preferential recombination between alternative DNA segments involved in gene activation by chromosomal rearrangement has been observed in organisms ranging from bacteria to humans. In the mammalian immune system, for example, there is a clear preference for which of many possible $\mathrm{V}$ regions become involved in recombination with a distant $\mathrm{J}$ sequence (Blackwell and Alt 1990; Knight and Becker 1990). Mechanisms of donor preference also appear to be important in the ordered expression of VSG genes in trypanosomes (Thon et al. 1990). In Schizosaccharomyces pombe, mating-type gene switching also involves an expressed mat locus and two unexpressed donors, though the DNA sequences and many aspects of the mechanism of switching are entirely different from S. cerevisiae (Klar 1992). mat switching in $S$. pombe also exhibits donor preference, which can be altered by a swi6 mutation that also apparently changes the chromatin structure in the $15-\mathrm{kb}$ interval between the two silent donors (Thon and Klar 1993). A thorough understanding of the way in which MATa activates a chromosomal region for recombination will prove to be of great importance in understanding these other types of programmed chromosomal rearrangements.

\section{Materials and methods}

\section{Strains}

Most strains were isogenic derivatives of strain DBY745 (ho MATa ade1 -100 leu2-3,112 ura3-52) or of HO strains NR2267B, NR238-7C, and NR272-19A, derived from an HO strain (Y55) and backcrossed at least six times against DBY745. Strain XW526, carrying a ring chromosome III, was also derived from the same genetic background (Haber et al. 1984). Strains H333 and $\mathrm{H} 334$ are heterothallic derivatives from Y55 crossed once with DBY745. The genotypes of the strains used are given in Table 3.
Table 3. Yeast strains

\begin{tabular}{|c|c|}
\hline Strain & Genotype \\
\hline DBY745 & ho $H M L \alpha$ MAT $\alpha$ HMRa adel-100 leu2-3,-112 ura3-52 \\
\hline $\mathrm{XW} 425$ & $\begin{array}{l}\text { ho HML } \alpha \text { MATa } H M R \alpha-B a m H 1: \text { ura3 ura3:- } \alpha 2: . U R A 3 \text { pJH727(GAL-HO } \\
\text { LEU2) ade1-100 leu2-3,-112 }\end{array}$ \\
\hline XW426 & $\begin{array}{l}\text { ho hmlA::ADE1 41kb::(LEU2,HMR } \alpha) \text { MATa } H M R \alpha-B a m H 1: \text { ura } 3 \\
\text { pJH132(GAL-HO URA3) ade1-100 leu2-3,-112 ura3-52 }\end{array}$ \\
\hline $\mathrm{XW} 427$ & $\begin{array}{l}\text { ho hmlA::ADE1 22kb::(LEU2,HMR } \alpha) \text { MATa HMR } \alpha \text {-BamH1::ura } 3 \\
\text { pJH132(GAL-HO URA3) adel-100 leu2-3,-112 ura3-52 }\end{array}$ \\
\hline$x W 429$ & $\begin{array}{l}\text { ho (C }{ }_{4} A_{2} \text { LEU2, all HMLdist. seq.4) HML } \alpha \text { MATa } H M R \alpha \text {-BamH1::ura3 } \\
\text { pJH132(GAL-HO URA3) ade1-100 leu2-3,-112 ura3-52 }\end{array}$ \\
\hline XW43I & $\begin{array}{l}\text { ho HML } \alpha \text { MATa HMR } \alpha \text {-BamH1: ura } 3 \text { pJH132(GAL-HO URA3) ade1-100 leu2- } \\
3,-1 / 2\end{array}$ \\
\hline$x W 441$ & $\begin{array}{l}\text { ho (hml }:: \text { LEU2 } 8 k b \text { HML prox. seq. } 4 \text { ) MATa HMR } \alpha \text {-BamH1::ura3 } \\
\text { pJH132(GAL-HO URA3) adel-100 leu2-3,-112 ura3-52 }\end{array}$ \\
\hline XW448 & 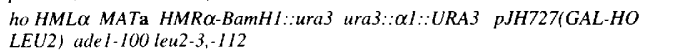 \\
\hline XW452 & $\begin{array}{l}\text { ho hmlD::ADE1 LEU2::HMR } \alpha \text { MATa HMR } \alpha \text {-BamHI::ura3 pJHI32(GAL-HO } \\
\text { URA3) adel-100 leu2-3,-112 ura3-52 }\end{array}$ \\
\hline XW453 & $\begin{array}{l}\text { ho hmlD::ADE1 his4::(LEU2,HMRQ) MATa HMRQ-BamH1:*ura3 } \\
\text { pJH132(GAL-HO URA3) adel-100 leu2-3,-112 ura3-52 }\end{array}$ \\
\hline$x W 490$ & $\begin{array}{l}\text { ho hmLA: (MATQ-inc,LEU2) MATa HMRQ-BamHI::ura3 pJHI32(GAL-HO } \\
\text { URA3) ade1-100 leu2-3,-112 ura3-52 }\end{array}$ \\
\hline XW533 & $\begin{array}{l}\text { ho (from the end to } 22 \mathrm{~kb} \Delta:: \text { ura } 3) \text { 4lkb: :(LEU2, HMR } \alpha) \text { MATa } \\
\text { HMR } \alpha \text {-BamH1::ura3 pJH132(GAL-HO URA3) ade1-I00 leu2-3,-112 ura3-52 }\end{array}$ \\
\hline XW486 & $\begin{array}{l}\text { ho HML } \alpha \text { his4: (HML } \alpha-H i n d H I, U R A 3) \text { MATa hmrA::ADE1 pJH727(GAL-HO } \\
\text { LEU2) adel-100 leu2-3,-112 lys5 ura3-52 }\end{array}$ \\
\hline XW526 & $\begin{array}{l}\text { ho HMR-HML } \alpha \text { fusion his4:-(HML } \alpha \text {-HindIII,URA3) MATa circular chromosome } \\
\text { pJH727(GAL-HO LEU2) ade } 1-100 \text { leu2-3,-112 lys2 or lys } 5 \text { ura3-52 }\end{array}$ \\
\hline NR226-7B & $\begin{array}{l}\text { HO HML } \alpha \text { MAT } \alpha \text { HMRa leu2-3,-112 lys } 5 \text { ura } 3-52 \\
\text { HO HML } \alpha \text { MATa HMRa leu2-3,-112 lys5 ura3-52 }\end{array}$ \\
\hline NR238-7C & $\begin{array}{l}\text { HO HMLQ MATQ HMRa adel leu2-3,-112 ly,5 ura3-52 } \\
\text { HO HMLQ MATa HMRa adel leu2-3,-112 lys } 5 \text { ura3-52 }\end{array}$ \\
\hline NR272-19A & 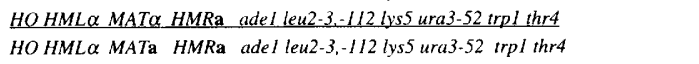 \\
\hline $\mathrm{XW} 153$ & 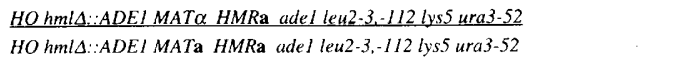 \\
\hline$x w 221$ & 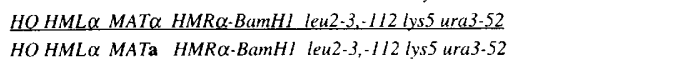 \\
\hline$x W 246$ & 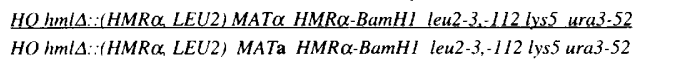 \\
\hline$x W 265$ & 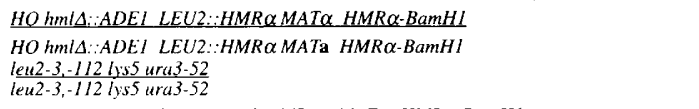 \\
\hline XW 348 & 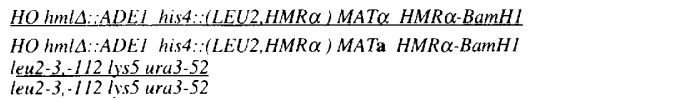 \\
\hline XW499 & 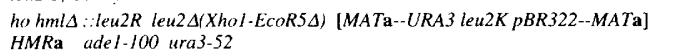 \\
\hline XW500 & 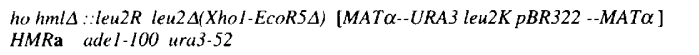 \\
\hline $\mathrm{XW} 498$ & 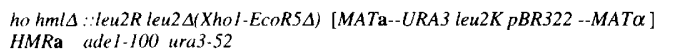 \\
\hline $\mathrm{XW} 440$ & $\begin{array}{l}\text { ho hmlA :leu2R leu2A(Xhol-EcoR5A) : (pBR322 URA3 leu2K) MATa HMRa } \\
\text { adel-100 thr4 ura3-52 }\end{array}$ \\
\hline $\mathrm{XW} 421$ & 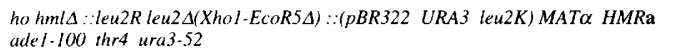 \\
\hline $\mathrm{XW} 485$ & $\begin{array}{l}\text { ho hml } \because \text { leu2R leu2A(Xhol-EcoR5A) MATa HMRa } \\
\text { ura3.52:(URA3 pBR322 leu2K) adel-100 thr } 4\end{array}$ \\
\hline XW456 & $\begin{array}{l}\text { ho hmlA : leu2R leu2A(Xho1-EcoR5A) MAT } \alpha \text { HMRa } \\
\text { ura3-52::(URA3 pBR322 leu2K) adel-100 thr } 4\end{array}$ \\
\hline H334 & $\begin{array}{l}\text { ho } H M L \alpha \text { leu } 2 K \text { [MATa-URA3 leu2R pBR322-MATa] HMRa adel-100 his6 } \\
\text { lys } 2 \text { metl3 ura3-52 }\end{array}$ \\
\hline $\mathrm{H} 333$ & $\begin{array}{l}\text { ho } H M L \alpha \text { leu } 2 K \text { [MAT } \alpha-\text { URA3 leu2R pBR322 } \cdots \text { MAT } \alpha] \text { HMRa adel-100 } \\
\text { lys } 2 \text { met13 trp5 ura3-52 }\end{array}$ \\
\hline XW529 & 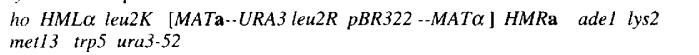 \\
\hline XW530 & $\begin{array}{l}\text { ho } H M L \alpha \text { leu } 2 K \text { [MATa-URA3 leu } 2 R \text { pBR322 --MATa] HMRa ade1 lys } 2 \\
\text { met/3 ura3-52 }\end{array}$ \\
\hline XW531 & 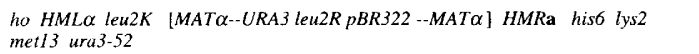 \\
\hline $\mathrm{XW} 412 \mathrm{a}$ & $\begin{array}{l}\text { ho HML } \alpha \text { leu2 } 2(X h o 1-E c o R 5 \Delta) 162 k b::(\text { leu2R pBR322 URA3) MATa } \\
233 k b::(\text { leu2K ADEI) HMRa adel-100 trpl ura3-52 }\end{array}$ \\
\hline $\mathrm{xW} 412$ & $\begin{array}{l}\text { ho HML } \alpha \text { leu2A(Xhol-EcoR5A) I62kb::(leu2R pBR322 URA3) MAT } \alpha \text {-BamHI } \\
233 k b::(\text { leu2K ADEI) HMRa adel-100 trpl ura3-52 }\end{array}$ \\
\hline XW508 & $\begin{array}{l}\text { ho } H M L \alpha \text { leu2 } \triangle(X h o 1-E c o R 5 \Delta)[M A T \mathbf{a}-U R A 3 \text { leu2K pBR322 -MATa] } \\
\text { Shmr:leu2R adel-100 lys5? ura3-52 }\end{array}$ \\
\hline Xw506 & 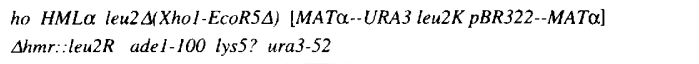 \\
\hline
\end{tabular}

$H M R \alpha$ was cloned from yeast by gap repair (Orr-Weaver and Szostak 1983) of a centromeric plasmid containing the regions flanking $H M R$ separated by an Xhol site that was used to linearize the plasmid (Abraham et al. 1984). The recovered $H M R \alpha$ 
gene was cloned as a HindIII fragment into a pGEM3Zf $|+|$ vector for further manipulation. The $H M R \alpha-\mathrm{B}$ allele was created by oligonucleotide-directed mutagenesis (Kolodeij and Young 1991) of $\mathrm{C} \rightarrow \mathrm{A}$ at position 658 in $\mathrm{Y} \alpha$ to create a BamHI site. $H M R \alpha-\mathrm{B}$ was introduced into the chromosome in place of $H M R$ a by the one-step gene replacement method (Rothstein 1983) of a HindIII fragment containing the URA3 gene inserted at the NruI site. The URA3 marker was then made $\mathrm{Ura}^{-}$by selection with 5-FOA (Boeke et al. 1987). Similar mutagenesis was performed to create $H M L \alpha-\mathrm{H}$ in which position 379 of $\mathrm{Y} \alpha$ was mutated $\mathrm{A} \rightarrow \mathrm{T}$ to create a HindIII site.

A cassette containing $H M R \alpha$ and $L E U 2$ was constructed in plasmid pXW145 (see Fig. 1C) and was integrated at other chromosomal locations by inserting it into a unique site of a previously cloned chromosomal segment. These regions were carried in a $\mathrm{pGEM} 3 Z \mathrm{f}|+|$ vector as $\sim 500$-bp PCR-amplified fragments, obtained by using oligonucleotide primers determined from the complete DNA sequence of chromosome III (Oliver et al. 1992). Thus, the cassette was inserted at a unique $A p a I$ site nucleotide 21,974 , at a unique ClaI site at nucleotide 41,404 , at a unique XhoI site at nucleotide 67,682 near HIS4, and at a unique XhoI site at nucleotide 90,286 near $L E U 2$. The fragments containing the target sequences flanking $L E U 2$ and $H M R \alpha$ were then transformed into yeast (Rothstein 1983). The $H M L \alpha-\mathrm{H}$ gene, plus an adjacent URA3 gene, was inserted at the XhoI site near HIS4 (nucleotide 67,682 ) in a similar fashion.

In some of these constructions, the $X$ hol fragment embracing $H M L$ was deleted and replaced by a 1.9-kb ADE1 gene (plasmid pXW123).

Terminal deletions of the left arm of chromosome III were constructed by targeting a DNA fragment carrying $0.3 \mathrm{~kb}$ of Tetrahymena $\mathrm{C}_{4} \mathrm{~A}_{2}$ repeats that serve to create a new yeast telomere (Dunn et al. 1984). The linearized transforming fragment contained the telomere sequences, a selectable LEU2 gene, and $\sim 500$ bp of homology to a particular site on chromosome III.

\section{LEU2 recombination}

In experiments involving leu2 heteroallele recombination, leu2- $R$ was inserted into a $h m l \Delta:: L E U 2$ deletion by the integration and popping-out of a URA3-leu2-R plasmid, as described previously (Lichten et al. 1987). In strains H333 and H334, introduction of $1 e u 2-K$ at $L E U 2$ (91 kb from the left telomere) was accomplished in the same fashion, as was the creation of $h m r \Delta:: l e u 2-R$. Insertions at MAT $(199 \mathrm{~kb})$ were done by the integration of a MAT-URA3-(leu2-K) pBR322 plasmid, as described previously (Lichten et al. 1987), to create a MATURA3-(leu2-K)-MAT duplication. A URA3-(leu2-K) plasmid was integrated into the ura3-52 locus on chromosome $\mathrm{V}$ to create ura3-52-pBR322-(leu2-K)-URA3 duplications. In strains $\mathrm{XW} 440$ and XW421 the same plasmid was inserted into a previously constructed partial deletion of leu2 to yield leu2spBR322-URA3-(leu2-K). PCR-amplified DNA from the regions of $162 \mathrm{~kb}$ on chromosome III was cloned into a URA3-(leu2-R) pBR322 plasmid, and this was integrated at nucleotide 162,870 to create a "162"-(leu2-R)-pBR322-URA3-"62" insertion. A PCR-amplified fragment of the $233-\mathrm{kb}$ region was cloned into a pGEM plasmid, and the XhoI-SalI leu2-K fragment that also carried an $A D E 1$ insert at the AfIII site (W.Y. Leung and J.E. Haber, unpubl.) was inserted at nucleotide 233,174 , to create the "233" insertion. The LEU2 genes in these constructions are all oriented with the $5^{\prime} \rightarrow 3^{\prime}$ direction being left to right on the chromosome in its standard prepresentation (Oliver et al. 1992), except for the $h m l \Delta::(l e u 2-R)$ and $249 \mathrm{~kb}:(l e u 2-K)$ insertions on chromosome III. Strains XW529, XW530, and XW531 are mei- otic segregants of a cross between $\mathrm{H} 333$ and $\mathrm{H} 334$, in which a crossover in the interval containing the duplicated MAT loci produces a nonmating (MATa-MAT $\alpha)$ segregant carrying both $M A T \mathbf{a}$ and $M A T \alpha$.

In strains XW499 and XW500, carrying $h m l \Delta::(l e u 2-R)$ and $M A T-U R A 3-($ leu2-K)-MAT, the two leu2 alleles are in opposite orientation. The proportion of gene conversion events at leu2- $K$ could be determined by placing Leu $^{+}$recombinants on 5-FOA to select $\mathrm{Ura}^{-}$derivatives that had popped out the duplication at MAT and became $\mathrm{Leu}^{-}$. A small fraction of the gene conversion events were associated with a reciprocal crossingover, such that a very large pericentric inversion was created. These could be recognized because the cells failed to yield many $\mathrm{Ura}^{-}$papillae on 5-FOA plates, as we have documented previously (Harris et al. 1993). Altogether, 4/196 Leu derivatives of the MATa strain XW500 and $1 / 196$ of the MAT $\alpha$ strain XW499 contained inversions. These were not counted in the analysis of which allele had converted.

\section{DNA analysis}

Preparation of yeast genomic DNA and Southern blot analysis was carried out as described previously (White and Haber 1990). A Y $\alpha$-specific DNA probe was derived from plasmid $\mathrm{pJH} 315$.

PCR amplification of $M A T \alpha$ or $M A T \alpha-\mathrm{B}$ derivatives, after switching from $M A T \mathrm{a}$, was accomplished by using primers KK200 (5-'CGACCACTCAAGAAAGA-3') and JK735 (5-'ATGTGAACCGCATGGGCAGT-3') to amplify a 769-bp $M A T \alpha$ specific DNA fragment. MAT $\alpha-\mathrm{B}$ contains a $B a m H I$ site that when cut, yields DNA fragments of 582 and $187 \mathrm{bp}$. Equivalent analysis was carried out when one donor carried $H M L \alpha-\mathrm{H}$, to yield MAT $\alpha-\mathrm{H}$ containing an HindIII site, after switching.

\section{Cell growth and induction MAT switching}

Cells were grown and sporulated at $30^{\circ} \mathrm{C}$. Induction of $\mathrm{HO}$ endonuclease was carried out in two ways. In some experiments, meiotic segregants carrying $M A T \mathrm{a}, H O$, and the donors indicated were dissected by micromanipulation and allowed to germinate and grow into nonmating colonies. These nonmating colonies result from the switch of MATa mother cells in the first several cell divisions to MAT $\alpha$ or $M A T \alpha-\mathrm{B}$ and their mating with remaining $M A T$ a daughter cells. The proportion of switches using MAT $\alpha$ or MAT $\alpha$-B was determined from densitometry of Southern blots of DNA cut with BamHI.

In most experiments a ho MATa strain carrying the URA3marked GAL::HO plasmid p)H132 (Nickoloff et al. 1989) or the similar LEU2-marked plasmid pJH727 was grown in YEP-lactate medium to which $2 \%$ galactose was added for $1.5 \mathrm{hr}$ to induce expression of $\mathrm{HO}$ endonuclease, as described previously (White and Haber 1990). The haploid MAT $\alpha$ or MAT $\alpha$-B derivatives were then analyzed by Southern blots or PCR amplification and BamHI cleavage.

\section{Northern blot analysis}

Ten-milliliter cultures of cells carrying $h m l \Delta:: L E U 2$ and deleted for the normal leu2 locus were grown in logarithmic phase to a density of $1 \times 10^{7}$ cells $/ \mathrm{ml}$ in YEPD. RNA was extracted according to Cross and Tinkelenberg (1991). In some experiments cells were first shifted from YEPD medium to minimal growth medium to allow greater expression of LEU2 and HIS4 mRNA. The Northern blots were probed with a ${ }^{32} \mathrm{P}$-labeled EcoRV-SalI fragment of LEU2 to measure the effect of mating type on transcription of a gene located near $H M L$, and with a ${ }^{32}$ P-labeled PvuII-ClaI fragment of HIS4, which was used to estimate the abundance of mRNA. The blots were counted by PhosophorImaging, as described above. 


\section{Acknowledgments}

Research was supported by the National Institutes of Health (grant GM20056). We thank Susan Lovett, Michael Lichten, and members of the Haber laboratory for their helpful comments on this paper.

The publication costs of this article were defrayed in part by payment of page charges. This article must therefore be hereby marked "advertisement" in accordance with 18 USC section 1734 solely to indicate this fact.

\section{References}

Abraham, J., K.A. Nasmyth, J.N. Strathem, A.J.S. Klar, and J.B. Hicks. 1984. Regulation of mating-type information in yeast. Negative control requiring sequences both $5^{\prime}$ and $3^{\prime}$ to the regulated region. $J$. Mol. Biol. 176: 307-331.

Blackwell, T.K. and F.W. Alt. 1990. Mechanism and developmental program of immunoglobulin gene rearrangement in mammals. Annu. Rev. Genet. 23: 605-636.

Boeke, J.D., F. Lacroute, and G.R. Fink. 1987. A positive selection for mutants lacking orotidine 5 '-phosphate decarboxylase activity in yeast. Mol. \& Gen. Genet. 197: 345-346.

Bone, J.R., J. Lavender, R. Richman, M.J. Palmer, B.M. Turner, and M.I. Kuroda. 1994. Acetylated histone $\mathrm{H} 4$ on the male X chromosome is associated with dosage compensation in Drosophila. Genes \& Dev. 8: 96-104.

Collins, I. and C.S. Newlon. 1994. Chromosomal DNA replication initiates at the same origins in meiosis and mitosis. Mol. Cell. Biol. 14: 3524-3534.

Connolly, B., C.I. White, and J.E. Haber. 1988. Physical monitoring of mating type switching in Saccharomyces cerevisiae. Mol. Cell. Biol. 8: 2342-2349.

Cross, F.R. and A.H. Tinklenberg. 1991. A potential positive feedback loop controlling CLN1 and CLN2 gene expression at the start of the yeast cell cycle. Cell 65: 875-883.

Dunn, B., P. Szauter, M.L. Pardue, and J.W. Szostak. 1984. Transfer of yeast telomeres to linear plasmids by recombination. Cell 39: 191-201.

Durand, J., J. Birdsell, and C. Wills. 1993. Pleiotropic effects of heterozygosity at the mating-type locus of the yeast Saccharomyces cerevisiae on repair, recombination and transformation. Mutat. Res. 290: 239-247.

Friis, J. and H. Roman. 1968. The effect of the mating-type alleles on intragenic recombination in yeast. Genetics 59: 33-36.

Haber, J.E. 1992. Mating-type gene switching in Saccharomyces cerevisiae. Trends Genet. 8: 446-452.

Haber, J.E., D.T. Rogers, and J.H. McCusker. 1980. Homothallic conversions of yeast mating-type genes occur by intrachromosomal recombination. Cell 22: 277-289.

Haber, J.E., P.C. Thorburn, and D.T. Rogers. 1984. Meiotic and mitotic behavior of dicentric chromosomes in Saccharomyces cerevisiae. Genetics 106: 185-205.

Harris, S.L., K.S. Rudnicki, and J.E. Haber. 1993. Gene conversion and crossing over during homologous and homeologous ectopic recombination in Saccharomyces cerevisiae. Genetics 135: 5-16.

Herskowitz, I. 1989. A regulatory hierarchy for cell specialization in yeast. Nature 342: 749-757.

Jensen, R. and I. Herskowitz. 1984. Directionality and regulation of cassette substitution in yeast. Cold Spring Harbor Symp. Quant. Biol. 49: 97-104.

Klar, A.J.S. 1992. Developmental choices in mating-type interconversion in fission yeast. Trends Genet. 8: 208-213.

Klar, A.J., J.B. Hicks, and J.N. Strathern. 1982. Directionality of yeast mating-type interconversion. Cell 28: 551-561.
Knight, K.L. and R. Becker. 1990. Molecular basis of the allelic inheritance of rabbit immunologlobulin VH allotypes: Implications for the generation of antibody diversity. Cell 60: 963-970.

Kolodeij, P.A. and R.A. Young. 1991. Epitope tagging and protein surveillance. Methods Enzymol. 191: 508-519.

Laurenson, P. and J. Rine. 1992. Silencers, silencing and heritable states. Microbiol. Rev. 56: 543-560.

Lea, D.E. and C.A. Coulson. 1949. The distribution of numbers of mutants in bacterial populations. J. Genet. 49: 264-285.

Lichten, M. and J.E. Haber. 1989. Position effects in ectopic and allelic mitotic recombination in Saccharomyces cerevisiae. Genetics 123: 261-268.

Lichten, M., R.H. Borts, and J.E. Haber. 1987. Meiotic gene conversion and crossing-over between dispersed homologous sequences occurs frequently in Saccharomyces cerevisiae. Genetics 115: 233-246.

Nickoloff, J.A., J.D. Singer, M.F. Hoekstra, and F. Heffron. 1989. Double-strand breaks stimulate alternative mechanisms of recombination repair. J. Mol. Biol. 207: 527-541.

Oliver, S.G., Q.J.M. van der Aart, M.L. Agostoni-Carbone, M. Aigle, L. Alberghina, D. Alexandraki, G. Antoine, R. Anwar, J.P.G. Ballesta, P. Benit et al. 1992. The complete DNA sequence of yeast chromosome III. Nature 357: 38-46.

Orr-Weaver, T. and J.W. Szostak. 1983. Genetic applications of yeast transformation with linear and gapped plasmids. Methods Enzymol. 101: 228-245.

Palladino, F., T. Larouche, E. Gilson, A. Axelrod, L. Pillus, and S.M. Gasser. 1993. SIR3 and SIR4 proteins are required for the positioning and integrity of yeast telomeres. Cell 75: 531-542.

Rothstein, R.J. 1983. One-step gene disruption in yeast. Methods Enzymol. 101: 202-211.

Strathern, J.N. 1989. Control and execution of mating type switching in Saccharomyces cerevisiae. In: Genetic recombination (ed. R. Kucherlapati and G.R. Smith), pp. 445-464. American Society for Microbiology, Washington, D.C.

Strathern, J.N. and I. Herskowitz. 1979. Asymmetry and directionality in production of new cell types during clonal growth: The switching pattern of homothallic yeast. Cell 17: 371-381.

Tanaka, K., T. Oshima, H. Araki, S. Harashima, and Y. Oshima. 1984. Mating type control in Saccharomyces cerevisiae: A frameshift mutation at the common DNA sequence, $X$, of the HMLa locus. Mol. Cell. Biol. 4: 203-211.

Thomas, B.J. and R. Rothstein. 1989. Elevated recombination rates in transcriptionally active DNA. Cell 56: 619-630.

Thon, G. and A.J.S. Klar. 1993. Directionality of fission yeast mating-type interconversion is controlled by the location of the donor loci. Genetics 134: 1045-1054.

Thon, G., T. Baltz, C. Giroud, and H. Eisen. 1990. Trypanosome variable surface glycoproteins: Composite genes and order of expression. Genes \& Dev. 4: 1374-1383.

Weiffenbach, B., D.T. Rogers, J.E. Haber, M. Zoller, D.W. Russell, and M. Smith. 1983. Deletion and single base-pair changes in the yeast mating type locus that prevent homothallic mating type conversions. Proc. Natl. Acad. Sci. 80: 3401-3405.

Weiler, K.S. and J.R. Broach. 1992. Donor locus selection during Saccharomyces cerevisiae mating type interconversion responds to distant regulatory signals. Genetics 132: 929-42.

White, C.I. and J.E. Haber 1990 . Intermediates of recombination during mating type switching in Saccharomyces cerevisiae. EMBO J. 9: 663-674. 


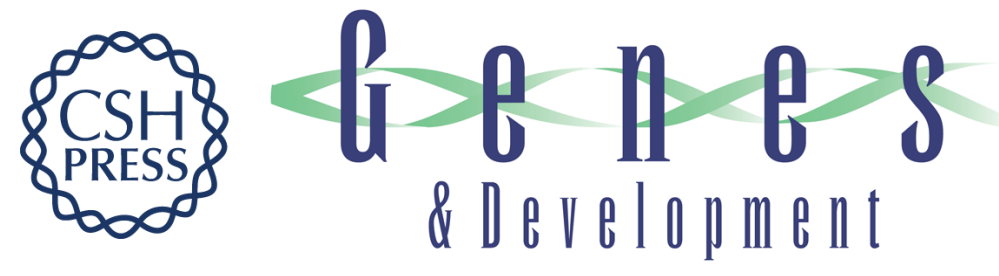

\section{MATa donor preference in yeast mating-type switching: activation of a large chromosomal region for recombination.}

$X$ Wu and $J$ E Haber

Genes Dev. 1995, 9:

Access the most recent version at doi:10.1101/gad.9.15.1922

References This article cites 37 articles, 15 of which can be accessed free at:

http://genesdev.cshlp.org/content/9/15/1922.full.html\#ref-list-1

License

Email Alerting

Service

Receive free email alerts when new articles cite this article - sign up in the box at the top right corner of the article or click here.

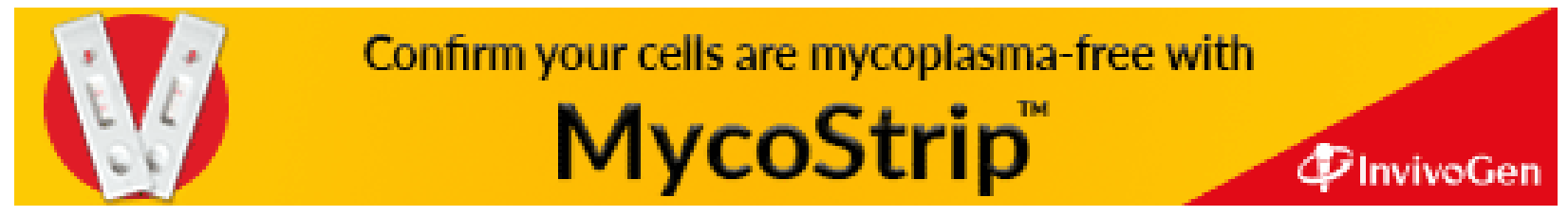

